\title{
Designing Hybrid Spaces for Learning in Higher Education Health Contexts
}

\author{
Jennifer K. Green ${ }^{1}$ (D)
}

Accepted: 7 October 2021 / Published online: 23 October 2021

(c) The Author(s), under exclusive licence to Springer Nature Switzerland AG 2021

\begin{abstract}
In Aotearoa New Zealand, undergraduate, professional health courses include social work, nursing, and biosciences courses that focus on learning how to support people with physical, mental, spiritual, and psychosocial/relational health and wellbeing concerns. Recently, the need for a nuanced understanding of how technologies might extend students' experiences across and beyond physical classrooms has emerged. Drawing on contemporary ecological perspectives in education, this paper emphasises that design for learning involves a complex web of elements. Anchored in practice theory, the paper uses the analytical lens of the Activity-Centred Analysis and Design (ACAD) framework to explore how tools, tasks, and various social arrangements influence student learning activity. A multiple case study investigated the experiences and insights of five higher education teacher-designers, discussing the relationship between features of course design and their perceived impact on emergent learning activity. Design elements are also discussed in relation to the experience of teacher-designers adapting and transitioning to hybrid environments during Covid-19, whilst working with diverse learners in different contexts and disciplines. Interviews with teacher-designers revealed what they believe contributes to productive learning activity, such as the importance of creating safe learning environments, an overall appreciation for the opportunity to use technology for teaching and learning, and their use of a heutagogical approach, which emphasizes the development of knowledge and skills for teaching in hybrid learning environments. The paper argues for practical and targeted support to acknowledge, encourage, and enhance teacher-designers' capabilities for transformational use of hybrid learning environments in health education.
\end{abstract}

Keywords Higher education · Undergraduates · Health education · ACAD framework · Hybrid learning design · Quality education

Jennifer K. Green

j.k.green@massey.ac.nz

1 School of Nursing, Massey University, Auckland, Aotearoa New Zealand 


\section{Introduction}

Over the past 40 years, undergraduate, health professional, higher education (HE) in Aotearoa New Zealand has been moving away from traditional pedagogical strategies centred around students listening to a lecture from an expert in a tiered seating theatre — the 'sage-on-the-stage' mode of teaching (King 1993). An important premise of effective healthcare is building rapport and establishing a therapeutic relationship between the provider and the recipient of care; so, in addition to traditional lessons in lecture theatres, students also attend sessions focused on developing skills and knowledge for clinical practice. These practical demonstrations are usually held in real healthcare settings with actual clients or in spaces set up to mimic healthcare rooms, such as a ward or clinic setting, with either students, actors, or manikins being the 'client'.

In real clinical settings, the mantra used to be 'see one', 'do one', and 'teach one' with students being put in a position of responsibility for direct client care, at times with minimal knowledge and preparation. There is now a growing awareness of the need to prepare students differently in the health disciplines with skills required in current clinical environments (such as critical thinking, collaboration, problem solving, and clinical decision-making) which has prompted a shift in teaching practices (Malik et al. 2017; Santos et al. 2019). Some of these changes include collaborative activities, testing the use of models of care on peers before using them on patients, practical application of theoretical ideas, linking content to real resources used in professional practice, and creating learning opportunities targeted on personal topics of interest (Shin et al. 2015; Smith and Kennedy 2019). Clinical practice in healthcare education acknowledges the importance of learning and practicing in safe simulation spaces prior to engaging with patients (Dubovi 2018; Shin et al. 2015; Shorey et al. 2019). As the current study shows, a range of learning resources and spaces offers students in health disciplines opportunities to practice the application of models of care and develop their skills in a safe and supported environment, whilst also encouraging them to experience a variety of social group formations well before interacting with actual patients. The healthcare courses within this study are part of health education and graduates of these courses will enter a wide range of careers which may not be necessarily focused on healthcare. Hereafter, the broader term of health education will be used.

Technology can be integrated in a range of scenarios in health education and can include a PowerPoint presentation in a lecture theatre, to highly complex activities, such as those involving the use of VR/AR and hi-fidelity simulations, to allow students to safely practice specific health procedures and processes (Dubovi 2018; Shorey et al. 2019; Taçgın 2020). However, as Bayne (2015) and Fawns (2019) argued, technology is only part of the picture, and called for more nuanced understanding of how multiple elements contribute to extending students' experiences across and beyond physical classrooms. This research draws on contemporary ecological perspectives that emphasise design for learning as part of a complex web of elements involving digital and material tools, tasks, 
and people and how these elements together might contribute to create productive learning environments (Carvalho et al. 2017; Damşa et al. 2019; Fawns et al. 2019). In this paper, the term 'hybrid learning' is used in relation to educational design and practice in postdigital spaces for learning. 'Hybrid learning' incorporates a variety of possible arrangements in health education, such as those combining digital and material elements, online and face-to-face spaces, and formal and informal learning and demonstrates how various forms of learning might coexist (Fawns 2019; Gil et al. 2021; Goodyear 2020). Indeed, Goodyear (2020) highlights the importance of theorising practices within learning space design and the many elements influencing the practical realities of hybrid learning for those involved in learning activities. In this article, 'teacher' refers to academic staff who support the learning of others, 'teacher-designers' are those who design for learning within their own courses, and 'learning developers' are specialists in course development and design for learning.

This article reports on interviews with five teacher-designers conducted at a time when courses were proceeding as face-to-face, on-campus teaching and learning activity but after a short period of pandemic restrictions in Aotearoa New Zealand. This research explores what these teacher-designers believe contributes to creating productive, hybrid learning environments in their undergraduate health education courses. The health education disciplines encompass social work, nursing, and biosciences taught in a higher education institution in Aotearoa New Zealand. The interviewees report on a broad scope of synchronous and asynchronous hybrid environments and include (i) on-campus activity at physical classrooms, lectures, tutorials, and simulation labs (each contingent on the people and technologies involved), (ii) courses in which the interactions and teaching mode relied heavily on technology via an Internet connection such as a learning management system (LMS) and video conference software, and (iii) course activity beyond these traditional university settings, such as an overnight marae-centred learning and living activity with lecturers, tutors (teaching assistants), and course participants sleeping, eating, and learning in the indigenous (Māori), space-based context of a noho marae (a livein, learning event that occurs over two days). All interviews were conducted after the emergence of Covid-19 pandemic and findings discuss health educators' experiences of teaching and learning with a focus on how these educators see the design of innovative hybrid environments contributing to their students' learning. The next section offers an overview of the use of technology in health education.

\section{Technology in Health Education}

Since the mid-1990s, the use of technology has existed within health education with varying degrees of acceptance. Research on the use of technology for teaching and learning includes its application to increase social interactivity within a community of inquiry (Hayes and Graham 2019); use of technology by students in assessing, engaging, and augmenting course resources (Henderson et al. 2017); and the flexibility afforded by virtual reality simulation in synchronous and asynchronous learning environments, which enable students to repeat the simulation as many 
times as they prefer, dependent on personal learning needs and the available time (Taçgın 2020). There are also studies focusing on the development of communication skills for virtual counselling using artificial intelligence (Shorey et al. 2019) and ways of using technology to enhance clinical reasoning (Dubovi 2018). Interprofessional communication in clinical settings was found to be enhanced through the use of a virtual hospital in SecondLife (Linden Lab 2016) that mirrored a real hospital (Prasolova-Førland et al. 2018). Santos et al. (2019) integrative review reports an increase in student engagement, critical thinking, and creativity with the use of innovative technology for Higher Education (HE) students. As the authors remind us, alongside these innovative uses of technology in HE, pedagogical dissonance experienced by some teachers also must be addressed, pointing to the importance of targeted professional development to support ongoing change in teaching and learning strategies.

Whilst many studies report positively on the incorporation of technology in learning contexts, diverse issues and barriers have also been identified. These include aspects such as digital literacy and inequalities (Czerniewicz 2018), limited access to resources (Dubovi 2018), physical discomfort and cyber-sickness (Prasolova-Førland et al. 2018), cognitive load (Abeysekera and Dawson 2015), the importance of information technology support, and the erroneous assumption that specific generations of learners will have transferrable digital skills (Green and Huntington 2017).

The literature goes beyond the use of technology for learning to include factors that mediate teaching and learning processes, such as:

- an understanding of andragogical pedagogy (centred around adult learners) (Smith and Kennedy 2019) and heutagogical principles and practices in learning (whereby the learner has agency on what, when and how they learn) (Blaschke 2012),

- the importance of learning facilitator and teacher confidence,

- experience with and awareness of alignment between technology, content and concepts being taught,

- and learner characteristics, expectations, and preparedness for the technology used (Green and Huntington 2017).

Literature on learning design and the use of educational technology not only suggest a number of pathways to optimal learning outcomes (Männistö et al. 2019; Merchant et al. 2014; Taçgın 2020) but also points to some constraints. There is growing disquiet about techno-centric views (Fawns 2019; Fawns et al. 2019) and concerns about using technology to foster individualism and hinder opportunities for collaboration (Vlachopoulos and Makri 2017). A further issue could be ethical concerns related to the collection of vast amounts of digital data as HE becomes more student-focused and metrics-centred (Williamson et al. 2020). In addition, there may be potential dissonance between teacher beliefs and the learning strategies they are attempting to incorporate (Selwyn 2016). There has been a lack of evidence for, and resistance to, the demonstration of underlying pedagogical considerations and designer actions (Boys 2015; Goodyear 2020; Jones and Czerniewicz 2011). Nevertheless, recent research in health education 
provides evidence of positive effects of hybrid environments in relation to both explicit (assessments) and implicit (professional behaviour, team dynamics, motivation, and engagement) outcomes (Donkin and Kynn 2021) and discusses ways of strengthening university teachers' design capabilities (Fawns et al. 2021).

Furthermore, it is important that health education aligns with UNESCO (2021) sustainable development goals, responding to the urgent need for quality education (SG4). This requires a robust re-evaluation of learning design in HE to prepare our future health workforce to make the most of rapid innovations in knowledge, skills, and practices and to provide quality, person-centred, empathetic, evidence-based healthcare to support good health and wellbeing (SG3). Research is warranted that incorporates a theoretical basis in learning design practices to investigate relationships between structural elements and students' co-configuration of learning environments.

\section{Framing Educational Design in Health Education}

Connecting practice to theory provides an effective way of studying how education practitioners collaborate to address problems, they encounter by either remaining with the status quo or inventing new strategies. Goodyear (2020) asserts that practice theory can provide a lens to examine both structural elements of a learning situation and individual agency as expressed by students. Such understanding can then inform educational strategy development and changes in policy to better support innovation in learning spaces and uses. Although Donkin and Kynn (2021) research has clear, present, team-based learning and futurefocused, professional practice outcomes, Goodyear notes that it is rare for learning design to incorporate learning opportunities for both the 'here and now' and transfer to wider learning contexts. The research reported in this article highlights design decisions made by lecturers in HE health courses as they address structural constraints and (re)organise their hybrid environments to support emergent learning activities focused on learner agency and meaning making.

The theoretical framing of this research draws on the Activity Centred Analysis and Design (ACAD) framework (Goodyear and Carvalho 2014), taking an ecological view to incorporate human and non-human factors influencing emergent learning within the learning process. Key to the analysis is the focus on the interplay and connections between digital and material tools, ideas, learning tasks, and people, as part of an assemblage of elements. ACAD has been used in numerous research studies in HE to foreground analysis and design for learning (Green et al. 2020; Sun 2018; Yeoman and Wilson 2019). Authors contend that the framework helps teacher-designers and learning developers to identify key elements within the structural design of a learning network and enables consideration of how these elements relate to the nature of student meaning-making. Figure 1 graphically represents ACAD's overarching key elements.

ACAD supports an analytical investigation through four main structural elements (Goodyear and Carvalho 2014): 

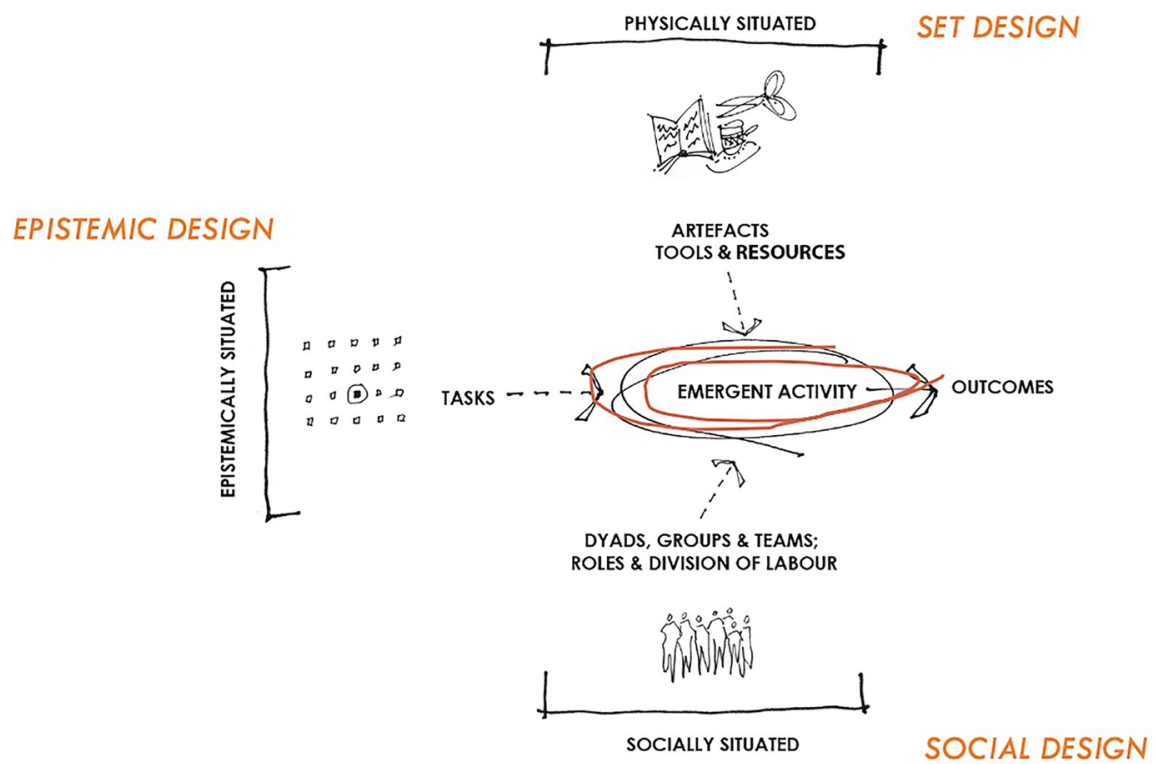

Fig. 1 ACAD framework (adapted from Goodyear and Carvalho 2014: 59)

- Epistemic design: or the design of learning tasks - e.g. organisation of knowledge, considerations about ways of knowing, the selection, sequencing, and pacing of information for meaning-making.

- Set design: or the design of elements in learning spaces (hybrid; online; face-toface) - e.g. digital and material tools, resources, artefacts, the furniture or tools used, how materials are positioned in a space.

- Social design: or the design of social arrangements for students - e.g. groups, dyads, scripted roles, divisions of labour, the nature of collaboration - in a group or in assessment, the role of the learner.

- Co-creation and co-configuration activity at learn time: refers to the co-creation of knowledge that emerges within a learning activity, the agency of learners.

In this research, ACAD supported the framing of the relationships between the three sets of design elements above (tools, tasks, and various social arrangements) and their influence on learn time activities. Set, social, and epistemic components are the 'designable elements' in a learning situation — the elements that are open to alteration or change. Learning activity is not designable, because what students will do cannot be entirely predicted or controlled in advance - activity is therefore emergent. As the emergent activities take place, designable elements are co-configured. Activities respond to an ecosystem of factors that exist in a learning space, at a particular time, location, and with a specific group of learners and teachers (Goodyear et al. 2021; Goodyear and Dimitriadis 2013). This research reports on the experiences and perceptions of teacher-designers transitioning to hybrid environments in courses that catered to diverse student demographics (e.g. ethnic groups - Māori, European, Pacifica, 
Asian - age ranges, prior experiences). The next section introduces the research design and methods.

\section{Research Design}

This article reports on four cases with five interviewees as part of a multiple case study (Stake 2006) project of undergraduate courses in three health disciplines encompassing social work, nursing, and biosciences in a multi-campus university in Aotearoa New Zealand. Health education topics have been taught at this institution since the mid-1970s. The tools used to gather data for each project case include interviews with health educators and students and observational analyses of course design, looking at how multiple elements are combined and contribute to productive learning hybrid environments. This article focuses on the assemblage of set, social, epistemic design elements, discussing key design elements identified through the analyses of interviews with five teacher-designers, and examining their views of four learning situations about how they saw design co-evolving through student activities.

\section{Data Collection and Analysis}

In this study, the researcher conducted five interviews with HE course teacher-designers in social work (2), nursing (1), and biosciences (2). Interviews lasted between 40 minutes and 1 hour, were recorded, and transcribed for analysis. Prior to the individual interviews, each research participant was provided with an information sheet that explained the focus of the research and presented the overarching concepts of the ACAD framework. Verbatim transcripts from interviews were analysed both manually and using NVivo software by the researcher. Using Lincoln and Guba (1985) criteria for establishing trustworthiness and Nowell et al. (2017) outline for thematic analysis, six themes were identified in the data. Tracy (2020) phronetic iterative approach helped identify descriptive primary-cycle codes in the data, with second-level analytical codes incorporating creative interpretation and theoretical knowledge. This approach to thematic analysis is concerned with developing knowledge and practical outcomes in a specific context for practical application and aligns well with Goodyear (2020) encouragement to employ practice theory in research to develop practical knowledge. Interview analysis maintains anonymity by referring to participant one as (P1) and so forth. The next section introduces course descriptions and then delves into emerging themes from interviews, including perceived effects of the necessary course changes due to Covid-19.

\section{Teacher-Designers and Course Design}

The five teacher-designers are female and have between 6- and 22-year experiences of teaching and designing for learning in higher education. Each undergraduate degree consists of a range of compulsory or elective, 15- to 45-credit courses that 
Table 1 Course details

\begin{tabular}{|c|c|c|c|c|}
\hline & Course 1 & Course 2 & Course 3 & Course 4 \\
\hline Participants & (P1) & $(\mathrm{P} 2)$ & (P3 and P4) & (P5) \\
\hline Undergraduate course area & Social work & Social policy & $\begin{array}{l}\text { Generic health sciences - } \\
\text { pharmacology }\end{array}$ & Nursing \\
\hline Year level & 3rd year & 4 th year & 2nd year & 3rd year \\
\hline Number of students & 59 & 8 & 175 (172 nursing students) & 152 \\
\hline
\end{tabular}

combine for a total of 360 credits. Table 1 summarizes general information about each of the four courses in the study.

Aspects related to the diversity of students in terms of ethnicity, age range, and gender are illustrated in Tables 2, 3, and 4, respectively. Table 2 shows that while the majority of students are from an NZ European background many students identify with two or three ethnicities. Nursing and pharmacology have lower percentages of Māori and Pacific Peoples than the current national population percentage, whilst social work has higher for these but a lower percentage of Asian ethnicity students (Statistics New Zealand 2019).

The age ranges within these courses are representative of students who are two or more years post high school, or who have returned to higher education study, to pursue a health career.

Students in health courses are typically allocated time at healthcare organisations for short periods over a semester in addition to attending lecturers, tutorials, and labs at the university. This is reflected in their timetable with an absence of scheduled lectures, tutorials, or labs for a period, which is usually planned well in advance for the entire cohort located at three campuses. However, each campus has dates that may differ due to local placement provider requirements. Table 5 highlights core design components of each course according to the epistemic, set, and social design dimensions of the ACAD framework.

This overarching structure includes adaptations to changed circumstances in health education contexts, in response to Covid-19 in Aotearoa New Zealand, which are apparent in the ways that these teacher-designers reconfigured their courses. Design transformations were evident when teacher-designers report having to

Table 2 Students' ethnicity (percentage)

\begin{tabular}{lcllrl}
\hline & Course 1 & Course 2 & Course 3 & Course 4 & Aotearoa NZ Popn \\
\hline Māori & $38.9 \%$ & $37.5 \%$ & $16 \%$ & $11.8 \%$ & $16.5 \%$ \\
NZ European & $71.2 \%$ & $75 \%$ & $76.6 \%$ & $71.7 \%$ & $70.2 \%$ \\
Pacific Peoples & $11.8 \%$ & & $5.1 \%$ & $5.1 \%$ & $8.1 \%$ \\
Asian & $5.1 \%$ & & $12 \%$ & $15.8 \%$ & $15.1 \%$ \\
$\begin{array}{l}\text { Middle Eastern/Latin } \\
\quad \text { American/African/ }\end{array}$ & $5.1 \%$ & & $3.4 \%$ & $5.3 \%$ & $2.7 \%$ \\
$\quad$ other & & & & & \\
Other European & $13.5 \%$ & $12.5 \%$ & $9.7 \%$ & $12.5 \%$ & (Included in other above) \\
\hline
\end{tabular}


Table 3 Students' age range (percentage)

\begin{tabular}{lllll}
\hline & Course 1 & Course 2 & Course 3 & Course 4 \\
\hline$<\mathbf{2 0}$ yrs & & & $30.3 \%$ & \\
$\mathbf{2 0 - 2 9} \mathbf{y r s}$ & $64.4 \%$ & $75 \%$ & $57.1 \%$ & $82.9 \%$ \\
$\mathbf{3 0 - 3 9} \mathbf{y r s}$ & $18.7 \%$ & $12.5 \%$ & $8 \%$ & $13.2 \%$ \\
$\mathbf{4 0} \mathbf{y r s}+$ & $17 \%$ & $12.5 \%$ & $4.6 \%$ & $4 \%$ \\
\hline
\end{tabular}

become familiar with new tools and software. Specific course design decisions had to be accelerated to accommodate new circumstances brought about by the consequences of the pandemic and a desire to be able to pivot to fully online learning should that be required. These are discussed as part of the emerging themes in the next section.

\section{Emerging Themes}

Emerging themes revealed a variety of digital and material, social and epistemic elements, and how these are constantly at play within these hybrid learning environments. The interviews were conducted after two Covid-19 lockdown periods in Aotearoa New Zealand, and, not surprisingly, teacher-designers reported on their self-perceptions of changed learning environments, mentioning aspects connected to set design enabling selection, sequencing and pacing of learning content, and social considerations focused on how to support students' learning. The interviewees were mindful of epistemic design to ensure consistency in translating research into educational practice. Enablers and constraints on course design and facilitation were also discussed.

\section{Theme 1: Transformations in Course Design}

Prior to the Covid-19 pandemic, course three (Pharmacology), a face-to-face course, was under review for transformation to hybrid mode. After the first Covid-19 outbreak, in the first half of 2020, the course was fast tracked to a fully online mode. The teacher-designers ( $\mathrm{P} 3$ and $\mathrm{P} 4)$ acknowledged that whilst this accelerated development was driven by factors outside of their control, it had resulted in a 'fantastic course site with some excellent, interactive learning resources' (P4). The planned redesign of this course involved the teacher-designers working alongside learning developers to incorporate a new HTML5 application of H5P learning activities in the learning management system (LMS). This H5P resource was seen as highly positive in that it

Table 4 Students' gender (percentage)

\begin{tabular}{lcllc}
\hline & Course 1 & Course 2 & Course 3 & Course 4 \\
\hline Female & $93.2 \%$ & $100 \%$ & $92 \%$ & $94.7 \%$ \\
Male & $6.8 \%$ & & $8 \%$ & $5.3 \%$ \\
\hline
\end{tabular}




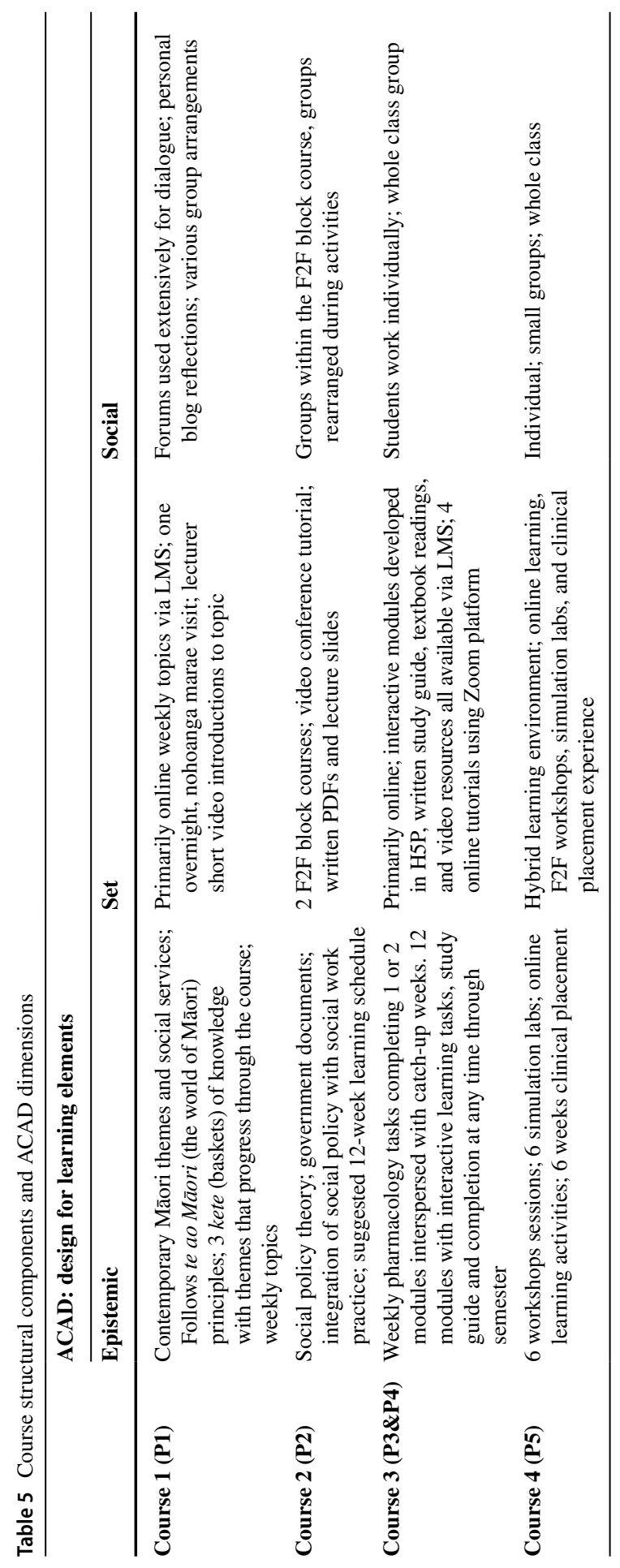


created a stable, consistent, and interactive learning resource (set) that included current discipline knowledge (epistemic) which students could access at a time and place that suited their clinical placement scheduling. However, the introduction of new types of learning tasks and software was also seen by the teacher-designers as a two-edged sword. On one hand, they welcomed the new format for presenting content in welldesigned modules, yet at the same time, they became acutely aware of a lack of professional development in the use and application of unfamiliar learning resources.

I guess other constraints are my ability to keep up with the technology. And how to use it, and not having the time to really receive training to do so. So ... the more you shift [to online] distance the more I think you have to become adept at knowing how to utilize these tools and when they're appropriate to use. (P4)

This statement aligns with Stec et al. (2019) who note that teachers most commonly use technology as a substitute for a lecture or an augmentation of learning rather than for transformational purposes and suggest that faculty need to be aware of, and take into account, diverse student learning needs in order to purposefully include learning tools. Additionally, the authors contend that teachers need time to explore how technology might support their teaching practice.

As previously mentioned, due to the relatively short periods of time for placements at healthcare organisations, flexibility of access to course resources was seen as highly important and drove the redesign of course three into a series of discrete topic-focused modules. At the start of the pandemic, these placements were cancelled, which created the need, in the latter half of 2020, to accommodate the large number of students requiring 'catch-up' placements on a rollingbasis throughout the semester. The result was that, at any point during the semester, there were always a few students on clinical placements and absent from the university's learning environment.

[The course is] structured as twelve modules ... there's a weekly activity or an activity associated with that module. And so, it meant that the [Campus B] students, who had a horrendous time [with the pandemic] because ... [throughout the whole semester groups] were on placement. And all the other variations in between could kind of work away. We opened the course site early and so some of them did start early. (P3)

In addition to having to create a modular course design, teacher-designers also worked on epistemic design while adapting tasks to Zoom tutorials (set design). This required changes in expectations of what they perceived to be lack of engagement. Whilst some teacher-designers noted the importance of having video cameras on during a session, they also acknowledged there were competing demands - too many small visuals, the need for high bandwidth, privacy implications, and effects of creating digital artefacts (videos) during the Zoom sessions. 
We'd have fifty or sixty, well you know by time you got those down even if they had their video going, you know you could barely see them could you. (P3)

When you put these lovely backgrounds behind you it's intense, video intensive, so it uses up bandwidth. (P2)

Because we record things online it provides a bit of hesitancy for those sort of personal experiences being verbalized. Because it is going to be Zoomed out to everybody. (P4)

Designing for hybrid learning necessitates consideration of how, when, and why students are seen or need to be seen, privacy issues, and psychological safety (Cleland et al. 2021). It is imperative that teachers communicate expectations with students and acknowledge concerns (Leung et al. 2021) and include learning design decisions that not only facilitate flexibility in access to resources (set design) but also include a pace and sequencing of tasks (epistemic design) to provide a safe environment (social design) and are all cognisant of the impact of transformation.

\section{Theme 2: Supporting and Challenging Students}

In designing for learning, the interviewees commented on the importance of creating an emotionally safe place for students where they could be challenged and yet feel able to engage and collaborate with each other (social design). The literature highlights the importance of teacher presence and the positive effect on learner's perceptions (Männistö et al. 2019; Smadi et al. 2019). This was evident in one of the courses which presents historical and recent colonisation experiences within Aotearoa New Zealand and invites students to learn about, consider, and challenge their perceptions of history, their place in it, and the ongoing effects of colonisation (epistemic design). As in other colonised countries, Aotearoa New Zealand is beginning to work through a process of acknowledging that indigenous people (Māori) must be self-determining in their own country. Jackson (2021) proposes embracing an ethic of restoration as a way of applying the Treaty of Waitangi (Te Tiriti o Waitangi) to address what Māori have lost at the hands of the colonisers and suggests that this provides an opportunity for all people to belong, to stand, and to come together mindful of their responsibilities to each other, to the environment, and to justice.

This restoration includes experiencing education beyond ingrained western ideas and frameworks. As such, the course uses a range of resources and tools, starting with familiar discussions in the digital (via an LMS) but moving onto experiencing physical spaces (noho marae) and material artefacts (marae carvings and other artefacts) located at the marae (set design). The teacher-designer acknowledged that the hybridity of the environment allows her students to be on a continuum process of decolonisation; 'you know I've started that fire, let's stoke it a little bit, you can sit in that squirm for a little bit. It's all good, but you know, let's keep moving on' (P1). As students move through the process of attending the noho marae, they develop their understanding to a point where 'they're transformed...it's a kind of liberation' (P1).

In other physical learning settings, lecturers also have an acute awareness of the importance of a positive challenge and of keeping a balanced view since what 
is a positive challenge for some may be quite distressing for others. One participant talked about disrupting the usual seating arrangements (set design) as a way of forming new discussion groups (social design) during a block course session (when students have a few days on campus and complete the remainder of the course via distance mode).

I know it puts them out of the comfort zone ... But when we're put outside of our comfort zone, we'll often learn and grow. But there will be some people who will be so scared of that, they can't learn and grow. So, you do have to be alert to that, and if somebody is not feeling comfortable you've got to think, 'Oh, do you want to just stay where you are, or do you want to move? Just move where you would like'. (P2)

Reformatting discussion groups can support multi-dimensional interactions within the class (social design), and such deliberate changes in key designable elements facilitate the emergent co-configuration of learning. This is noted within the nursing simulation lab sessions where the opportunity for repeated practice (set, social and epistemic design) contributes to enhancing future patient safety (Shorey et al. 2018). Repeated practice helps students to develop skills in a practice setting (emergent, co-configuration) before applying these in a real, clinical setting.

It's a safe place. You would never want them to go out into clinical and have to do a patient assessment for the first time, like that, without actually going, 'stop, this is what you need to be doing', and then working through that whole cycle of learning for the students. (P5)

Supporting students is a complex endeavour. As teacher-designers noted the demands of their profession, they showed an awareness about the increasing need to act, at times quickly, in support of student learning and direct them to student services; all whilst acknowledging the personal toll incurred in managing these often-complex student situations.

It's being an expert in the area, an expert in teaching, an expert in the online environment, and an expert in student health and wellbeing sometimes. Which I'm not, so I clearly say, you know, 'this is where you go for that'. But it still affects us. (P4)

The importance of lecturer involvement and tangible and timely support in all aspects of hybrid learning cannot be underestimated. This was evident in the way that $\mathrm{P} 2$ recognised the need for creating an environment in which students want to learn and are supported to co-configure their learning.

I think students learn more from each other than they do from us ... someone was saying, ... 'I expect to be taught'. It was in conversation here around my bench, we were chatting away, and I said, 'No, you don't, you don't. I don't teach! I try to create an environment within which you can learn, so I try to make it as interesting as possible that you want to learn'. (P2) 
The creation of moments for interactions and support for student engagement were also highlighted. The approach of one of the lecturers was grounded on a te ao Māori (the Māori worldview) principle of the entire group moving together (social design). Māori are a collective society, and the group moving forward together is more important than an individual progressing. When collaborating and engaging in course forums, students shared knowledge about readings, videos, whakatāuki (proverbs), and historical records, and this was seen as essential for the collective coconstruction of knowledge by students. Course content was presented sequentially, with the subsequent topic being revealed once the whole group had engaged with the current topic's forum discussion (epistemic design). In this course, the forum was an essential and integral component of set design and influenced the social construction of emergent activities to enhance active engagement in a HE course, a finding aligning with Smith and Kennedy (2019) research into authentic learning with an andragogical focus. The level of student engagement in P1's course called for a commensurate level of teacher involvement to support and create links between student postings. Such involvement was significant at the beginning of the course while norms and expectations were being developed and tapered off, as students became enthused with the discussions and aware of the engagement expectations. The teacher-designer reported a student saying that they were really addicted, like the student could not 'wait to get up in the morning to see, to read all of the posts... the forums' (P1).

In the pharmacology course, student engagement and interactions involved video conferencing via Zoom teaching sessions, and in the nursing course, this was primarily via on-campus laboratory sessions (set design). The teacher-designers in these two courses typically used the LMS forums primarily as a medium to disseminate course events, information, and organisational aspects of the course, rather than for course discussions (epistemic design).

\section{Theme 3: Designing for Teamwork and Maintaining Continuity}

Each of the courses included experienced teaching staff, which one could argue potentially accounts for effective teaching team environments and successful collaboration. When discussing an overnight, noho marae, P1 noted that, 'It's all run the same, so we all know our jobs... I take the lead role... I go down the night before, I spend some time with [names colleague], we get it all done' (P1). Another teacherdesigner compared their undergraduate course to other courses which might involve ten or more teaching staff. In commenting on their own course, they noted, 'I think we are very lucky that ... there are only four of us. And we're pretty much all on the same page' (P3).

Typically, different teachers enact a course design slightly differently with different cohorts - depending on what students do, think, and feel at learn time. These differences may have a more pronounced impact when more than one teacher is involved with a specific cohort or when teaching is distributed across multiple campuses. Reinterpretation of what is core in the content contributes to students experiencing varying degrees of content consistency - course design alone does not 
translate into a homogenous experience for all. Teaching is also highly dependent on a lecturer's expertise, experience, and confidence. Participant 5 (P5) notes that this was evident in a series of observed nursing simulation labs. The first lab was facilitated and debriefed by P5, who is experienced in facilitating simulation labs. The remaining labs were facilitated by a clinical expert, unfamiliar with simulation pedagogy, who did not appear to understand the importance of specific, design elements associated with simulation components. In hindsight, P5 realised that there was typically insufficient time to adequately train staff in effective simulation facilitation. 'When you get some person who's new, or filling in for you, to do the simulation, depending on the education that persons' had around how to do the simulation, the students could have a completely different experience.' (P5)

For in-person simulation labs, P5 noted that having well-prepared, skilled, debriefing facilitation is imperative. However, even though Mapes (2019) proposes that teaching consistency is reliant on the stability of teaching staff in HE, the reality is that HE contexts are often subject to the vagaries of short-term, non-tenured contracts. Staff may be asked to 'fill in' a vacant post without an ideal level of expertise whilst acknowledging that someone is required to be 'in front' of the class. In contrast to having an inexperienced lone lecturer, teacher-designers valued a fully online course using a team-teaching approach that enables less experienced staff to be mentored remotely by experienced colleagues.

Many educators who shifted their courses to the online mode during the pandemic have reflected on several challenges and constraints (Rapanta et al. 2021). The HE sector in Aotearoa New Zealand has been financially affected by Covid-19. The constant challenge of income for many institutions was exacerbated with the decline in international student enrolments due to travel restrictions. In addition, HE institutions consistently balance a variety of, at times, competing demands, including room space, timetabling, and staffing. As this research involved different university campuses in different geographic regions, there was also the need for flexibility in order to accommodate different lockdown restrictions. Teachers in the study reported additional constraints arising from managing clinical placements and the need to remove students from courses for weeks at a time.

When I first started it was always, I think five weeks we had of teaching and then placement, and then it became that two of the campuses had five weeks and then [Campus C] only had four weeks. And ... it was becoming more difficult to align those and things. So, we were discussing potentially going online and we just made the decision ... to give it a go. (P3)

This was combined with restrictions on travel, so the move to online modules decreased opportunities for face-to-face, on campus workshops or block courses.

Well, I think, having the, having the experience of Covid this last year ... [which occurred after the initial face-to-face orientation] and also having the experience of having solely online classes, I think that when you have met the group, as a group, at the beginning of the Semester ... that you've got a group, you can see the group and the group sees you. They've seen everyone else, and then to bring them together online is so much easier than if you just start cold 
from not having that group experience first and I think that if we were going to move to online learning I would be advocating for wherever possible, and it's not always possible, I know. (P2)

It was clear that Covid-19 related constraints had significant influence on course design for these teacher-designers. For example, P3 and P4 worked together to reconfigure their design into modules giving students access at a time and place that suited their clinical schedules. Epistemic design was explicit in both the structure of the design and on explanations to students for employing this modular approach.

They go in and it's easy to navigate through the content. And they can see where they're going with it, and they can see what they've done, where they're going ... And it all makes sense like there's a rationale behind everything that's on there ... I think they understand that there's a pathway through it. How to get through it and why it's there, and that's not often found in courses. (P4)

\section{Theme 4: Improvisational Theatre-Redesigning for Online Co-configuration}

The requirement (at times of heightened Covid-19 responses) to transition from on campus, co-located teaching to synchronous video conferencing on Zoom and physically distanced teaching (set design), also posed salient challenges for teachers, which reverberated on aspects of epistemic and social design. One teacher-designer likened this to moving from improvisational theatre to a scripted, blended approach. They talked about a loss of spontaneous responses to perceived student needs; they could no longer use known resources and experience developed over years of teaching, which in the physical scenario enabled instant responses to student learning needs (Fawns 2019). In comparison, similar responses in the virtual space (Zoom), required prior thought and careful planning for multiple eventualities that may not actually be required.

That's why face-to-face is somewhat easier as well. Because I've got other tools that are quickly brought to play. For example, I might start a discussion, or I might have an online clicker thing, or I might have some worksheets I could pull out. Or I could say, 'hey let's build up a table and we'll each contribute to that table', and those kinds of things are often ad hoc depending upon what kind of feedback I'm getting in the class. And where I see the gaps are, and online you have to have all that prepared ahead of time, right? And you have to assume that they're needed when they may not be needed ... But that ability to sort of say actually let's create a table and do that out in your breakout rooms or whatever. For me that is quite challenging to do ad hoc without having prepared that and actually thought about that ahead of time. (P4)

This quote highlights a spontaneous aspect of the pre-Covid-19 teaching experiences and suggests an interplay of digital and material elements that can coalesce at learn time. For this teacher-designer, students' co-creation was perhaps more noticeable at the physical scenario, where it was easier to 'read the room' and orchestrate 
learning activity with suggestions for bringing new elements into action, that is to 're-design on the fly'. For this teacher-designer, it was perhaps easier to see how they could quickly re-configure epistemic design (bringing new tasks) in response to students' activity, in the face-to-face scenario. In contrast, the assemblage of epistemic, set, and social elements in the fully online scenario and its impact on students' activity seemed less obvious. This calls for a reorientation of how co-configuration may also become more evident for these teachers, in fully online learning spaces.

Some teacher-designers expressed a sense of loss in the move away from on campus, in-person teaching sessions, and the resultant loss of their live improvisations in response to audiences and their perceived engagement. Being a teacher in front of an audience was key to their professional persona and raised metaphysical dilemmas. In addition, the move to a remote audience, in which visual and body language cues were less evident (Weitze et al. 2013), resulted in teacher-perceived barriers to effective teaching and learning. This highlights the importance of teacher-designers' awareness of not only what is designable within the ecology of learning elements, but also what is nondesignable, that is, the student activities at learn time. Co-configuration of designable elements is influenced by the learners and the context and is contingent on the autonomy and agency of learners during this emergent phase (Sun and Goodyear 2020).

\section{Theme 5: Bringing Research into Authentic Learning Spaces}

Higher education contexts endeavour to provide epistemic content and discussions that are informed by research findings and literature. Most of the interviewees commented on the satisfaction of both students and teachers being able to translate research findings into practical application. For one teacher, her research occurred alongside her involvement with the course:

It's put my $\mathrm{PhD}$ into practice. So, all my hard research, and stuff, it's put into practice, ... I was studying alongside doing this course. So, I was able to, not trial and error, but I was able to put things in and go, 'oh wow, that made that impact', you know, so this was kind of my ultimate. (P1)

P5 became aware of a framework for nursing care and described how the framework informed the organisation of aspects in set, social, and epistemic design throughout the course.

When I was in my discussion of my PhD I came across that Fundamentals of Care framework. Which is a really good way to think about how you look after patients, and I can see how that Fundamentals of Care can really frame undergraduate nursing. Because it doesn't matter where you are, if you don't do the fundamentals of care then you're actually missing some components of nursing. (P5)

The translation of this research into learning design and practice was noted by P5 as being evident in the emergent activity of students during the course introduction while using this Fundamentals of Care framework (see Theme 6). 
Bringing research into the learning space was evident also in the way that one lecturer invited students to research a social policy topic of personal interest and then guided their evaluation in a comparative analysis of national and international policy. Such an example illustrates andragogical learning because of its focus on the learning needs of adults, through the use of authentic contexts, considering their prior experiences and enabling learner agency, overall capitalising on internal motivations for self-directed learning (Knowles et al. 2020).

'What's your interest? Tell me what you're interested in? ...So, how are we going to evaluate this policy?' It's a comparative evaluation, so they have to compare this policy in New Zealand, with a policy overseas... So, what is there that we could bring back from overseas to New Zealand, ...we can learn from overseas, but what are the pitfalls of trying to transpose a policy from there to here? (P2)

The focus on authentic learning, developing skills in literature searches, and critically appraising policy for relevance to social work contexts resonates with the findings of Smith and Kennedy (2019) in a nursing context, who emphasised the importance of students experiencing learning in ways that authentically reflect a professional context. The teacher-designers included current research literature and their personal research findings into their epistemic design to create a bridge between research and professional practice.

\section{Theme 6: Student Activity and Indicators of Learning}

The ACAD framework emphasises that design elements should be seen in relation to the undesignable emergent activity of students, to their experiences in co-creating knowledge (Goodyear and Carvalho 2014; Goodyear and Dimitriadis 2013). Although this paper has not discussed observational data from student activity, some passages of interviews with teacher-designers highlighted their impressions of such activity and their elation when indicators of learning were evident. The teacher-designers reported that this ranged from students overcoming challenges such as engaging with each other, the teacher, the learning activities, and discipline knowledge.

Every year it's amazing the stuff they come up with. It's really cool. So, that's the beginning of informing it, and then looking at how the Fundamentals of Care can inform their practice for working with people with an acute illness. (P5)

At other times, indicators of learning occurred in assessments. One teacher specifically guided students in the use of literature to demonstrate their own understanding,

So, I don't want to know what the literature ... tells you. I want to know what you're thinking. You can back it up with the literature, but I want to know what you're thinking ... over the years that I've done this, I've always had students 
that have gone, 'Wow, I didn't know that!' Or like it's kind of transformed their way of thinking. (P1)

Similarly, another teacher-designer spoke of her surprise about what students learn.

Some of those final reports that I read are just so amazing and you're doing this, 'Ohh! I never thought of that!' Because I think that's amazing when students write things that you go, 'Oh well isn't that interesting! I hadn't thought of that!', or 'I didn't know that' ... (mimics keyboard entering) ... 'I'll just check that they got that right!' (P2)

The interview findings indicate that all teacher-designers deeply considered multiple elements in set, social, and epistemic design which together seem to have contributed to well-rounded course sites, useful resources, and productive learning experiences. Within the ecology of elements involved, the ability to meet with students in-person, co-located, was perceived as highly influential on subsequent interactions and engagement. Having research active lecturers, who bring research into the learning environment and enable students to apply it in practice, was also perceived as beneficial in preparing students to work on authentic professional settings. The hybrid learning environments appeared to be moderated by teacher engagement, their expertise and fluidity in the use of technology, as well as the stability of their teaching team. The introduction of new technologies, however, often required showcasing and modelling of its application, so teachers could see examples of best practice.

\section{Conclusion}

Teaching practices in hybrid learning environments require discipline expertise in combination with careful design, pedagogical strategies, facilitation techniques, technology skills, and platform management expertise. The study suggests a few core principles to guide the design and facilitation in hybrid learning environments. Enhancing flexibility for students' access and engagement includes finding ways of challenging their thinking whilst maintaining their safety. Creating authentic indicators of learning with direct relevance and applicability in graduate, professional healthcare contexts requires translation of discipline theory into practice. Incorporating the benefit of indigenous ways of learning, as shown in P1's account of an authentic, te ao Māori (the Māori worldview) learning philosophy, can benefit all learners and embrace their diversity. As Fawns et al. (2021) remark, the focus on inclusivity requires continuous dialogue with students, flexible designs for learning, and adaptability at learn time.

As part of the global response to Covid-19, courses in HE were transformed to meet public health physical distancing requirements, clinical placement degree requirements, and practical course delivery considerations. Educators had scant time to prepare for these changes; however, most seemed to have managed to adjust elements and accommodate requirements. The teacher-designers in this study frequently remarked on their process for PD, expressing ambivalence about the often 
opportunistic and urgent nature of their preparation to teach in the current environment. Pre-pandemic, PD was commonly a result of individual choices or, at times, necessity, and ranged from sitting and observing how other expert teachers organised and managed their learning environments, through to trial and error, often resulting in significant frustration until proficient. PD needs to reflect a heutagogical approach (Blaschke 2012) to teachers' own learning, whereby professional learning experiences address immediate issues such as taking on a new course, preparation of resources (e.g. edit and upload a recorded video tutorial), or learning how to manage video conferencing platforms in order to manage set design aspects and to support excellent epistemic and social design. However, the urgency for course transformation arising from Covid-19 pandemic responses has challenged purposeful and planned PD.

Overall, living and learning in postdigital times require transformations that acknowledge the hybridity of learning environments or the ecology of elements at play (Carvalho et al. 2017; Damşa et al. 2019; Fawns et al. 2019). It calls for assessing and enhancing ways of seamlessly integrating technology, whilst applying andragogical principles, valuing disciplinary expertise, and supporting lecturers through PD specific to their contexts. The teacher-designers in this study commented on a lack of organised and ongoing, personal learning and development (PD), with most noting that they taught themselves through trial-and-error or developed skills as a result of attendance at a conference simulation workshop. This highlights an opportunity to offer teachers a self-assessment tool (Sailer et al. 2021) so that they can check areas of current expertise and areas for PD. Teaching staff are often time-poor and need agency in planning where, when and how they access opportunities to observe, self-assess, identify learning needs, access targeted PD, and explore how design might support hybrid learning. This could require working on authentic design tasks, finding ways of scaffolding design work, and promoting dialogue with teacher-peers to help teacher-designers better understand the relationship between what is designed ahead of time and what the teacher-designers leave to unfold at learn time (Fawns et al. 2021). It could also include development of a personal teaching tool-kit for hybrid environments that can be used on a 're-design on the fly' basis dependent on student learning needs.

This research highlights the real-world perspective and design decisions (Goodyear 2020) of HE lecturers in health education courses. Further research in this project will look at perspectives of students and support staff and their experiences of the ecology of elements that contribute to productive hybrid learning in health education contexts.

\section{Declarations}

Competing Interests Not applicable

\section{References}

Abeysekera, L., \& Dawson, P. (2015). Motivation and cognitive load in the flipped classroom: Definition, rationale and a call for research. Higher Education Research \& Development, 34(1), 1-14. https://doi.org/10.1080/07294360.2014.934336. 
Bayne, S. (2015). What's the matter with 'technology-enhanced learning'? Learning, Media and Technology, 40(1), 5-20. https://doi.org/10.1080/17439884.2014.915851.

Blaschke, L. M. (2012). Heutagogy and lifelong learning: A review of heutagogical practice and selfdetermined learning. International Review of Research in Open and Distance Learning, 13(1), $56-71$.

Boys, J. (2015). Building better universities: Strategies, spaces, technologies. Abingdon: Routledge.

Carvalho, L., Goodyear, P., de Laat, M. (2017). Place-based spaces for networked learning. New York: Routledge. https://doi.org/10.4324/9781315724485.

Cleland, J., Yang, L., \& Rosby, L. (2021). Cameras on or off: What is the question? Medical Teacher, 1. https://doi.org/10.1080/0142159X.2021.1892049.

Czerniewicz, L. (2018). Inequality as higher education goes online. In N. B. Dohn, S. Cranmer, J. Sime, M. De Laat, \& T. Ryberg (Eds.). Networked Learning Research in Networked Learning (pp. 95-106). Cham: Springer International. https://doi.org/10.1007/978-3-319-74857-3_6.

Damşa, C., Nerland, M., \& Andreadakis, Z. E. (2019). An ecological perspective on learnerconstructed learning spaces. British Journal of Educational Technology, 50(5), 2075-2089. https://doi.org/10.1111/bjet.12855.

Donkin, R., \& Kynn, M. (2021). Does the learning space matter? An evaluation of active learning in a purpose-built technology-rich collaboration studio. Australasian Journal of Educational Technology, 37(1), 133-146. https://doi.org/10.14742/ajet.5872.

Dubovi, I. (2018). Designing for online computer-based clinical simulations: Evaluation of instructional approaches. Nurse Education Today, 69, 67-73. https://doi.org/10.1016/j.nedt.2018.07. 001 .

Fawns, T. (2019). Postdigital education in design and practice. Postdigital Science and Education, 1(1), 132-145. https://doi.org/10.1007/s42438-018-0021-8.

Fawns, T., Aitken, G., \& Jones, D. (2019). Online learning as embodied, socially meaningful experience. Postdigital Science and Education, 1(2), 293-297. https://doi.org/10.1007/s42438-019-00048-9.

Fawns, T., Markauskaite, L., Carvalho, L., \& Goodyear, P. (forthcoming 2021). $\mathrm{H}_{2} \mathrm{~m}$ pedagogy: Designing for hybrid learning in medical education. In E. Gil, Y. Mor, Y. Dimitriadis, \& C. Köppe (Eds). Hybrid learning spaces. Cham: Springer International.

Gil, E., Mor, Y., Dimitriadis, Y., \& Köppe, C. (Eds.). (forthcoming 2021). Hybrid learning spaces. Cham: Springer International.

Goodyear, P. (2020). Design and co-configuration for hybrid learning: Theorising the practices of learning space design. British Journal of Educational Technology, 51(4), 1045-1060. https://doi.org/10. 1111/bjet.12925.

Goodyear, P., \& Carvalho, L. (2014). Framing the analysis of complex learning environments. In L. Carvalho \& P. Goodyear (Eds.), The architecture of productive learning networks (pp. 48-70). New York: Routledge. https://doi.org/10.4324/9780203591093.

Goodyear, P., Carvalho, L., \& Yeoman, P. (2021). Activity-Centred Analysis and Design (ACAD): Core purposes, distinctive qualities and current developments. Educational Technology Research and Development, 69(2), 445-464. https://doi.org/10.1007/s11423-020-09926-7.

Goodyear, P., \& Dimitriadis, Y. (2013). In medias res: Reframing design for learning. Research in Learning Technology, 21(0), 1-13. https://doi.org/10.3402/rlt.v21i0.19909.

Green, J. K., Burrow, M. S., \& Carvalho, L. (2020). Designing for transition: Supporting teachers and students cope with emergency remote education. Postdigital Science and Education, 2(3), 906-922. https://doi.org/10.1007/s42438-020-00185-6.

Green, J. K., \& Huntington, A. D. (2017). Online professional development for digitally differentiated nurses: An action research perspective. Nurse Education in Practice, 22, 55-62. https://doi.org/10. 1016/j.nepr.2016.11.009.

Hayes, C., \& Graham, Y. (2019). Social interactivity as driver and digital technology as vehicle: Facilitating affective domain learning for undergraduates. Higher Education, Skills and Work-based Learning, 10(2), 313-324. https://doi.org/10.1108/HESWBL-05-2019-0068.

Henderson, M., Selwyn, N., \& Aston, R. (2017). What works and why? Student perceptions of 'useful' digital technology in university teaching and learning. Studies in Higher Education, 42(8), 15671579. https://doi.org/10.1080/03075079.2015.1007946.

Jackson, M. (2021). Where to next? Decolonisation and the stories in the land. In B. Williams (Ed.), Imagining decolonisation. Wellington, NZ: Bridget Williams Books.

Jones, C., \& Czerniewicz, L. (2011). Theory in learning technology. Research in Learning Technology, 19(3), 173-177. https://doi.org/10.1080/21567069.2011.632491. 
King, A. (1993). From sage on the stage to guide on the side. College Teaching, 41(1), 30-35.

Knowles, M. S., Holton III, E. F., Swanson, R. A., \& Robinson, P. A. (2020). The adult learner: The definitive classic in adult education and human resource development. 9th Ed. New York: Routledge.

Leung, H. T. T., Bruce, H., \& Korszun, A. (2021). To see or not to see: Should medical educators require studentstoturnoncamerasinonlineteaching?MedicalTeacher,43(9), 1099.https://doi.org/10.1080/0142159X. 2021.1873258 .

Lincoln, Y. S., \& Guba, E. G. (1985). Naturalistic inquiry. Newbury Park, CA: SAGE.

Linden Lab. (2016). About Linden Lab. http://www.lindenlab.com/about. Accessed 30 May 2021.

Malik, G., McKenna, L., \& Griffiths, D. (2017). Using pedagogical approaches to influence evidencebased practice integration - processes and recommendations: Findings from a grounded theory study. Journal of Advanced Nursing, 73(4), 883-893. https://doi.org/10.1111/jan.13175.

Männistö, M., Mikkonen, K., Kuivila, H. M., Virtanen, M., Kyngäs, H., \& Kääriäinen, M. (2019). Digital collaborative learning in nursing education: A systematic review. Scandinavian Journal of Caring Sciences, 34(2), 280-292. https://doi.org/10.1111/scs.12743.

Mapes, M. (2019). Unjust precarity: Contingent faculty and the introductory communication course. Wicked problems forum: Contingent labor in higher education. Communication Education, 68(2), 246-252. https://doi.org/10.1080/03634523.2019.1571213.

Merchant, Z., Goetz, E. T., Cifuentes, L., Keeney-Kennicutt, W., \& Davis, T. J. (2014). Effectiveness of virtual reality-based instruction on students' learning outcomes in K-12 and higher education: A meta-analysis. Computers \& Education, 70, 29-40. https://doi.org/10.1016/j.compedu.2013.07.033.

Nowell, L. S., Norris, J. M., White, D. E., \& Moules, N. J. (2017). Thematic analysis: Striving to meet the trustworthiness criteria. International Journal of Qualitative Methods, 16(1), 1-13. https://doi.org/ $10.1177 / 1609406917733847$.

Prasolova-Førland, E., Steinsbekk, A., Fominykh, M., \& Lindseth, F. (2018). Practicing interprofessional team communication and collaboration in a smart virtual university hospital. In V. L. Uskov, J. P. Bakken, R. J. Howlett, \& L. C. Jain (Eds.), Smart Innovation, Systems and Technologies (pp. 191224). https://doi.org/10.1007/978-3-319-59454-5_7.

Rapanta, C., Botturi, L., Goodyear, P., Guardia, L. \& Koole, M. (2021). Balancing technology, pedagogy and the new normal: Post-pandemic challenges for higher education. Postdigital Science \& Education. https://doi.org/10.1007/s42438-021-00249-1.

Sailer, M., Stadler, M., Schultz-Pernice, F., Franke, U., Schöffmann, C., Paniotova, V., Husagic, L., \& Fischer, F. (2021). Technology-related teaching skills and attitudes: Validation of a scenario-based self-assessment instrument for teachers. Computers in Human Behavior, 115. https://doi.org/10. 1016/j.chb.2020.106625.

Santos, J., Figueiredo, A. S., \& Vieira, M. (2019). Innovative pedagogical practices in higher education: An integrative literature review. Nurse Education Today, 72, 12-17. https://doi.org/10.1016/j.nedt. 2018.10.003.

Selwyn, N. (2016). Is technology good for education? Malden, MA: Polity Press.

Shin, S., Park, J. H., \& Kim, J. H. (2015). Effectiveness of patient simulation in nursing education: Metaanalysis. Nurse Education Today, 35(1), 176-182. https://doi.org/10.1016/j.nedt.2014.09.009.

Shorey, S., Ang, E., Yap, J., Ng, E. D., Lau, S. T., \& Chui, C. K. (2019). A virtual counselling application using artificial intelligence for communication skills training in nursing education: Development study. Journal of Medical Internet Research, 21(10), e14658. https://doi.org/10.2196/14658.

Shorey, S., Kowitlawakul, Y., Devi, M. K., Chen, H. C., Soong, S. K. A., \& Ang, E. (2018). Blended learning pedagogy designed for communication module among undergraduate nursing students: A quasi-experimental study. Nurse Education Today, 61, 120-126. https://doi.org/10.1016/j.nedt.2017. 11.011.

Smadi, O., Parker, S., Gillham, D., \& Müller, A. (2019). The applicability of community of inquiry framework to online nursing education: A cross-sectional study. Nurse Education in Practice, 34, 17-24. https://doi.org/10.1016/j.nepr.2018.10.003.

Smith, S. B., \& Kennedy, S. (2019). Authentic teaching to promote active learning: Redesign of an online RN to BSN evidence-based practice nursing course. Journal of Professional Nursing, 36(2), 56-61. https://doi.org/10.1016/j.profnurs.2019.07.005.

Stake, R. E. (2006). Multiple case study analysis. New York: The Guilford Press.

Statistics New Zealand. (2019). New Zealand's population reflects growing diversity. https://www.stats. govt.nz/news/new-zealands-population-reflects-growing-diversity. Accessed 13 September 2021. 
Stec, M., Smith, C., \& Jacox, E. (2019). Technology enhanced teaching and learning: Exploration of faculty adaptation to ipad delivered curriculum. Technology, Knowledge and Learning, 25(3), 651-665. https://doi.org/10.1007/s10758-019-09401-0.

Sun, S. Y. H. (2018). Student configuration and place-making in fully online language learning. Computer Assisted Language Learning, 31, 932-959. https://doi.org/10.1080/09588221.2018.1466808.

Sun, S. Y. H., \& Goodyear, P. (2020). Social co-configuration in online language learning. Australasian Journal of Educational Technology, 36(2), 13-26. https://doi.org/10.14742/ajet.5102.

Taçgın, Z. (2020). The perceived effectiveness regarding Immersive Virtual Reality learning environments changes by the prior knowledge of learners. Education and Information Technologies, 25(4), 2791-2809. https://doi.org/10.1007/s10639-019-10088-0.

Tracy, S. J. (2020). Qualitative research methods: Collecting evidence, crafting analysis, communicating impact. Hoboken, NJ: Wiley Blackwell.

UNESCO. (2021). The Sustainable Development Agenda. https://www.un.org/sustainabledevelopment/ development-agenda. Accessed 30 May 2021.

Vlachopoulos, D., \& Makri, A. (2017). The effect of games and simulations on higher education: A systematic literature review. International Journal of Educational Technology in Higher Education, 14(1), 1-33. https://doi.org/10.1186/s41239-017-0062-1.

Weitze, C. L., Ørngreen, R., \& Levinsen, K. (2013, 30-31 October 2013). The global classroom video conferencing model and first evaluations. In I. M. Ciussi \& M. Augier (Eds.), Proceedings of the 12th European conference on E-Learning SKEMA Business School. Reading, UK: Academic Conferences and Publishing International.

Williamson, B., Bayne, S., \& Shay, S. (2020). The datafication of teaching in Higher Education: Critical issues and perspectives. Teaching in Higher Education, 25(4), 351-365. https://doi.org/10.1080/ 13562517.2020.1748811.

Yeoman, P., \& Wilson, S. (2019). Designing for situated learning: Understanding the relations between material properties, designed form and emergent learning activity. British Journal of Educational Technology, 50(5), 2090-2108. https://doi.org/10.1111/bjet.12856.

Publisher's Note Springer Nature remains neutral with regard to jurisdictional claims in published maps and institutional affiliations. 